\title{
A COMPARATIVE STUDY BETWEEN ENDOSCOPIC AND MICROSCOPIC TYMPANOPLASTY
}

\author{
Dhungana A, Joshi RR, Rijal AS, Shrestha KK, Maharjan S
}

Department of Otorhinolaryngology \& Head and Neck Surgery, Nepal Medical College Teaching Hospital, Attarkhel, Gokarneshwor-8, Kathmandu, Nepal.

\begin{abstract}
A study to compare tympanoplasty between endoscopic and microscopic approach was conducted at NMCTH. Patients diagnosed as chronic otitis media - mucosal type with age of 13 years and above were included in the study. Audiometric test was done before and 6 weeks after surgery. Seventy cases were included for the study with random allocation of cases each in endoscope group and microscopic group respectively. Graft uptake results were assessed after 6 weeks and postoperative hearing were evaluated and compared within and between the two groups. In endoscopic group and microscopic group, the graft uptake rate was $91.4 \%$ and $88.5 \%$ respectively with no significant difference $(p=0.71)$ in the graft uptake rate between the groups. The mean pre and post-operative air bone gap in endoscopic group and microscopic group were $34.59 \mathrm{~dB} \pm 8.02,21.97 \pm 8.60 \mathrm{~dB}$ and $32.42 \pm 10.08 \mathrm{~dB}, 18.55 \pm 8.49 \mathrm{~dB}$ respectively. This showed a highly significant difference in both groups $(p<0.001)$, showing improvement in the hearing after surgery in both the groups. The mean air bone gain were $12.62 \mathrm{~dB}$ and $13.87 \mathrm{~dB}$ in endoscopic and microscopic group respectively, with no significant difference between the groups ( $p=0.553)$. The graft uptake rate and hearing results with endoscopic technique is comparable to that of microscopic technique. However, the endoscopic technique requires shorter operative time than the microscopic technique. Therefore, we recommend the use of endoscope for tympanoplasty in hospital as well as in camps.
\end{abstract}

\section{KEYWORDS}

Chronic otitis media, endoscope, large perforation, microscope, pure tone audiometry, tympanoplasty

\section{CORRESPONDING AUTHOR}

Dr. Anup Dhungana,

Department of Otorhinolaryngology \& HNS,

Nepal Medical College Teaching Hospital, Attarkhel,

Gokarneshwor-8, Kathmandu, Nepal.

Email: dhunganaanup@hotmail.com

ORCID ID: 0000-0003-1480-1178 


\section{INTRODUCTION}

Tympanoplastyis defined as an operationinvolving reconstruction of the tympanic membrane and/or the ossicular chain. Myringoplasty is a tympanoplasty without ossicular reconstruction. Over the years many methods have been used for closing perforations. The most widely used and accepted method is underlay graft of temporalis fascia or sometimes perichondrium. ${ }^{1}$

Tympanoplasty was first described by Wullstein ${ }^{2}$ and Zollner ${ }^{3}$ in 1952 as the mainstay for tympanic membrane reconstruction. Different grafting materials that have been used for reconstruction are mesenchymal tissues, including vein, fascia, perichondrium and periosteum. . $^{4-10}$ But the most widely used graft material is temporalis muscle fascia. ${ }^{11}$

Usually, myringoplasty and middle ear surgery is performed with the aid of microscope. However, a microscope offers a straight-line view, which limits the visual field in the deep recesses of the middle ear. If a canal is narrow or protruding, the traditional technique requires a procedure to expose and visualize the structures behind it. Therefore, middle ear surgery is increasingly being performed endoscopically, ${ }^{12}$ and it has recently been suggested that endoscopy could replace the use of a microscope. ${ }^{13}$ Endoscopes offer a wide field of view with magnification. Surgeons can also rapidly obtain close-up and wide-angle views by inserting or withdrawing the endoscope, whereas a microscope requires adjustment. Further, surgeons can rotate an angled endoscope to obtain all-round vision, thereby enabling visualization of the anterior margin of the perforation; the anterior canal wall, attic, and hypotympanum in the middle ear can also be visualized.

This study was designed to compare the results of tympanoplasty with endoscopic and microscopic approach.

\section{MATERIALS AND METHODS}

This randomized control trial was done at Nepal Medical College Teaching Hospital (NMCTH), Department of Otorhinolaryngology and Head and Neck Surgery from March 2017 to February 2019.

This study included patients aged 13 years and above diagnosed with chronic otitis media mucosal type with large perforation and patients willing to undergo tympanoplasty in the hospital. Patients with subtotal or total perforation of TM, more than half perforation of TM, revision cases, anterior margin involvement, and moist middle ear mucosa were included as large perforation. ${ }^{14-21}$ Patient with frank otorrhea, small perforation equal to or less than half of TM and patients with sensorineural hearing loss were excluded from the study.

Randomisation was done by odd and even number system, the odd number underwent microscopic technique whereas the even number underwent endoscopic technique. Temporalis fascia graft was used in all cases. Graft uptake and post-operative hearing was tested after 6 weeks of surgery.

Results were analysed as time taken for surgery, graft uptake rate and change between pre- and post-operative hearing. Data were analyzed using Fisher's exact test, Chi square test, dependent and independent ' $t$ ' test on a SPSS statistical package version 16.0. The level of statistical significance was set at the $p<0.05$.

Ethical approval was taken from the Institutional Review Committee of NMCTH.

\section{RESULTS}

Seventy patients were included in the study after fulfilling the inclusion criteria. Randomisation was done in odd even number system. Odd number were included in microscopic group whereas even number were included in endoscopic group.

The graft uptake rate in endoscopic group was $32(91.4 \%)$ cases and microscopic group was 31 $(88.5 \%)$ cases. The graft failure rate was $3(8.6 \%)$ and $4(11.5 \%)$ in endoscopic and microscopic group respectively. The difference in graft uptake results between these two groups was not found to be statistically significant $(\mathrm{p}=0.71)$.

To compare the hearing results, only the graft uptake cases were taken into account. In endoscopic group 32 and in microscopic group 31 were included for hearing results.

In endoscopic group the mean pre-operative air conduction threshold was $51.06 \mathrm{~dB}(\mathrm{SD}=8.28)$ and post-operative air conduction threshold was $36.69 \mathrm{~dB}(\mathrm{SD}=9.84)$. The mean pre-operative air bone gap was $34.59 \mathrm{~dB}(\mathrm{SD}=8.02)$ and postoperative air bone gap was $21.97 \mathrm{~dB}(\mathrm{SD}=8.60)$. Hearing improvement after surgery was found to be statistically highly significant $(p<0.001$ ). In microscopic group the mean pre-operative air conduction threshold was $48.45 \mathrm{~dB}$ (SD =14.41) and post-operative air conduction threshold was $33.52 \mathrm{~dB}(\mathrm{SD}=14.96)$. The mean pre-operative air bone gap was $32.42 \mathrm{~dB}(\mathrm{SD}=10.08)$ and postoperative air bone gap was $18.55 \mathrm{~dB}(\mathrm{SD}=8.41)$. Hearing improvement after surgery was found to be statistically highly significant $(p<0.001)$. 
The mean pre-operative Pure Tone Audiogram Air Conduction (PTA-AC) threshold was found to be $51.06 \mathrm{~dB}$ and $48.45 \mathrm{~dB}(\mathrm{p}=0.395)$, post-operative PTA-AC threshold was $36.69 \mathrm{~dB}$ and $33.52 \mathrm{~dB}$ $(\mathrm{p}=0.323)$, pre-operative Pure Tone Audiogram -Air Bone (PTA-AB) Gap was $34.59 \mathrm{db}$ and $32.42 \mathrm{~dB}(\mathrm{p}=0.346)$, post-operative PTA-AB Gap was $21.97 \mathrm{~dB}$ and $18.55 \mathrm{~dB}(\mathrm{p}=0.118)$ and mean Air Bone (AB) gain was $12.62 \mathrm{~dB}$ and $13.87 \mathrm{~dB}$ $(p=0.553)$ in endoscopic group and microscopic group respectively. Applying independent T-test, the difference in means between the groups in each category was not found to be significant statistically.

The mean operative time in endoscopic approach was 64.63 min where as in microscopic approach, it was 77.31 minutes. Applying independent T-test, the difference in means between the groups was found to be statistically significant $(\mathrm{p}<0.001)$, (Fig. $1)$.

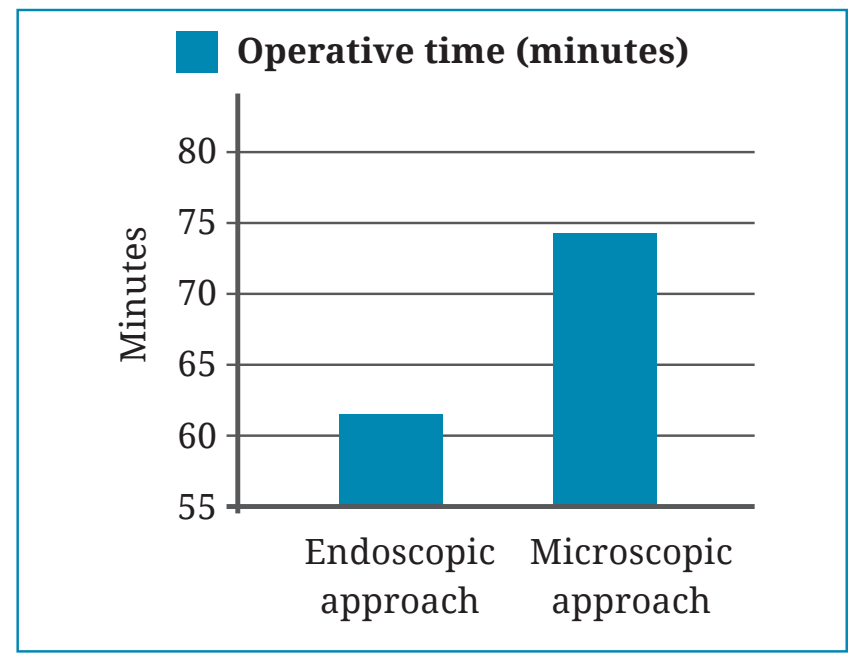

Fig. 1: Operative time of surgery

\section{DISCUSSION}

Tympanoplasty was done using microscope in the earlier days, but now endoscope has been introduced for doing tympanoplasty. There were 70 cases in our study out of which 33 were male and 37 were female (Fig. 2). In endoscopic group, graft uptake rate was $91.4 \%$ where as in microscopic group, it was $88.5 \%$ which is similar to a study done by Gaur et $a l^{22}$ who included 60 patients, 38 males and 22 females with surgical success rates of $26(88 \%)$ patients in the endoscope group and 27 (90\%) patients in microscope group respectively.

Lakpathi et $a l^{23}$ compared the outcomes of the endoscopic versus microscopic approach myringoplasty in 60 patients (40 male and 20 female) with age range of 15-55 years. Group 1 underwent myringoplasty with an endoscopic

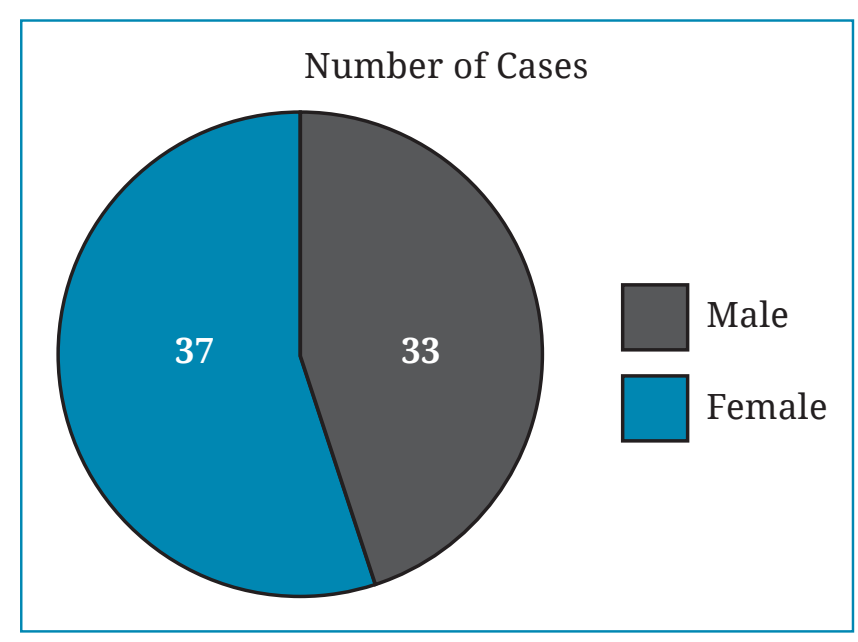

Fig. 2: Gender distribution

technique ( $\mathrm{n}=30$ ), and Group 2 underwent myringoplasty with the conventional microscopic technique $(n=30)$. Temporalis fascia graft was used in both groups. In both groups, the postoperative air-bone gap (ABG) was significantly lower than the preoperative ABG. There were no significant differences between the preoperative and postoperative $A B G$ values (in $\mathrm{dB}$ ) in either group. The mean operative duration in Group 1 (96.32 min) was significantly lower than that in Group 2 (136.09 min).

The difference between the perforation conditions (larger vs. smaller) was not significant in either group. The preoperative and postoperative increases in the ABG were associated. At the end of 6 months all (100\%) patients in the Group 1 rated their cosmetic result as excellent as compared in the Group 2. Unlike the microscope, the endoscope is easily transportable and hence is ideal for use in ear surgery camps conducted in remote places. In patients undergoing myringoplasty, especially if the external ear canal is narrow and the anterior canal wall is prominent, the endoscopic and microscopic approaches appear to give equal results in terms of easy visualization of the entire tympanic membrane and no requirement for extra intervention to evaluate the ossicular system. A shorter operative duration and excellent cosmetic result is an advantage of the endoscopic Myringoplasty technique.

Choi et al ${ }^{24}$ compared 73 patients ( 35 males and 38 females) who underwent type I tympanoplasty. The subjects were classified into two groups; endoscopic tympanoplasty (ET, $n=25)$, microscopic tympanoplasty (MT, n=48). The perforation size of the tympanic membrane in ET and MT group was $25.3 \% \pm 11.7 \%$ and $20.1 \% \pm 11.9 \%$, respectively $(\mathrm{P}=0.074)$. Mean operation time of MT $(88.9 \pm 28.5$ minutes) was longer than that of the ET $(68.2 \pm 22.1$ minutes) with a statistical significance $(\mathrm{P}=0.002)$. Graft success rate in the ET and MT group were $100 \%$ and $95.8 \%$, respectively; the values were 
not significantly different $(\mathrm{p}=0.304)$. Pre- and postoperative audiometric results including bone and air conduction thresholds and air-bone gap were not significantly different between the groups. In all groups, the postoperative airbone gap was significantly improved compared to the preoperative air-bone gap. Immediate postoperative pain was similar between the groups. However, pain of 1 day after surgery was significantly less in the ET group.

Huang et $a l^{25}$ concluded endoscopic approach for tympanoplasty offers superior visualization and shorter operative time than conventional surgery, in addition to equal hearing outcomes and perforation.
The findings of our study is similar to that of the above studies. Both the hearing results and graft uptake rate was similar in both the techniques however, the operative time was shorter in endoscopic technique than the microscopic technique. As the endoscope are lighter, easily transportable and shows better visualization and shorter operative time, we recommend the use of endoscope will be better in hospital as well as in camps.

Endoscopic and microscopic technique had similar hearing results and graft uptake rate, but the operative time was shorter in endoscopic than microscopic technique.

\section{REFERENCES}

1. George G. Browning, Justin Weir, Gerard Kelly and Iain R.C. Swan. Chronic Otitis Media. Scott-Brown's Otorhinolaryngology Head and Neck Surgery, $8^{\text {th }}$ edition. CRC Press, Florida, USA; 2019: 977-1020.

2. Wullstein HL. Functional operations in middle ear with split-thickness skin graft. Arch Otorhinolaryngol 1952; 161: 422-35.

3. Zollner F. The principles of plastic surgery of the sound-conducting apparatus. J Laryngol Otol 1955; 69: 657-9.

4. Shea JJ. Vein graft closure of eardrum perforations. J Laryngol Otol 1960; 74: 358-62.

5. Tabb HG. Closure of perforations of the tympanic membrane by vein grafts: a preliminary report of 20 cases. Laryngoscope 1960; 70: 271-4.

6. Heerman H. Tympanic membrane plastic repair with temporalis fascia. Hals Nas Ohren 1960; 9: 136-9.

7. Salen B. Tympanic membrane grafts of fullthickness skin, fascia and cartilage with its perichondrium, an experimental and clinical investigation. Acta Otolaryngol Suppl Stockh 1968; Suppl 244: 5-73.

8. Claros-Domenech A. 100 tympanoplasties practiced with the aid of the use of free periosteal membrane graft. Rev Laryngol Otol Rhinol (Bord.) 1959; 80: 917-21.

9. Bocca E, Cis C, Zernotti E. L'impiego di lembi liberi di periostio nella tympanoplastica. Arch Ital Otol 1959; Suppl40: 205.

10. Nissen AJ, Nissen RL, Yonkers AJ. A historical review of the use of bone and cartilage in otologic surgery. Ear Nose Throat J 1986; 65: 493-6.

11. Glasscock ME, House WF. Homograft reconstruction of the middle ear. Laryngoscope 1968; 78: 1219-25.

12. Harugop AS, Mudhol RS, Godhi RA. A comparative study of endoscope assisted myringoplasty and micrsoscope assisted myringoplasty. Indian $J$ Otolaryngol Head Neck Surg 2008; 60: 298-302.

13. el-Guindy A. Endoscopic transcanal myringoplasty. J Laryngol Otol 1992; 106: 493-5.
14. Yung M, Vivekanandan S, Smith P. Randomized study comparing fascia and cartilage grafts in myringoplasty. Ann Otol Rhinol Laryngol 2011; 120: 535-41.

15. Haitham AA, Ali AMM, Raghdan MA, Khalid DH. Temporalis fascia versus cartilage graft in myringoplasty. Jordan Med J 2014; 48: 113-20.

16. Gerber MJ, Mason JC, Lambert PR. Hearing results after primary cartilage tympanoplasty. Laryngoscope 2000; 110: 1994-9.

17. Ben Gamra O, Mbarek C, Khammassi K et al. Cartilage graft in type I tympanoplasty: audiological and otological outcome. Eur Arch Otol Rhinol Laryngol 2008; 265: 739-42.

18. Dornhoffer J. Hearing results with cartilage tympanoplasty. Laryngoscope 1997; 107: 1094-9.

19. Khullar NK, Kotwal S, Paul J. Composite graft tympanoplasty. JK Practitioner 2000; 7: 121-4.

20. Akhihiro K, Yumi M, Tadashi D et al. Results and devices of simple myringoplasty with fibrin glue. Otology Japan 2006; 16: 81-6.

21. Couto L, Marquezini RMS, Oliveira JA, Massuda ET. Outcome of inlay tragus cartilage myringoplasty. Braz J Otolaryngol 2004; 70: 494-8.

22. Gaur RS, Tejavath P, Chandel S. Comparative study of microscopic-assisted and endoscopic-assisted myringoplasty. Indian J Otol 2016; 22: 177-82.

23. Lakpathi G, Reddy LS, Anand. Comparative Study of Endoscope Assisted Myringoplasty and Microscopic Myringoplasty. Indian J Otolaryngol Head Neck Surg 2016; 68: 185-90.

24. Choi N, Noh Y, Park W et al. Comparison of Endoscopic Tympanoplasty to Microscopic Tympanoplasty. Clin Exp Otorhinolaryngol. 2017; 10: 44-9.

25. Huang TY, Ho KY, Wang LF, Chien CY, Wang HM. A Comparative Study of Endoscopic and Microscopic Approach Type 1 Tympanoplasty for Simple Chronic Otitis Media. J Int'l Adv Otol 2016; 12: 2831. 